Asian Review of Social Sciences

ISSN: 2249-6319 Vol. 9 No.2, pp. 14-19

(C) The Research Publication, www.trp.org.in

\title{
Effective Strategies for Development of Tourism Sector: A Critical Review
}

\author{
Shazia Hassan \\ Research Scholar, Department of Management Studies, University of Kashmir, Hazratbal, Srinagar Kashmir, \\ Janmmu and Kashmir, India \\ E-mail: bareerahmalik786@gmail.com
}

\begin{abstract}
The tourism sector is gaining increased importance for the economic development of countries around the world. Tourism sector has emerged as an important sector of Indian economy and contributes substantially in the country's Foreign Exchange Earnings. Tourism is the third largest foreign exchange earner after gems, jeweler and readymade garments and represents vibrant economic sector with overwhelming growth and revenue generation. The purpose of this paper is to give a theoretical overview of the classical and contemporary business strategies that can be implemented in a more or less modified form for the development of tourism sector. Keywords: strategies, tourism, J\&K, destination strategy
\end{abstract}

\section{INTRODUCTION}

The world tourism industry has remained resilient over the recent years and has shown remarkable growth. As per World Travel \& Tourism Council (WTTC) the tourism industry on an average has grown annually at an rate of $2.8 \%$. It is reported that in the year 2012, more than 1 billion international tourist arrivals were recorded globally, which is 39 million more than the arrivals recoded in 2011, i.e. an increase of 4\%(WTTC Annual Report, 2010).

This increase is due to the positive results noted in most of the regions throughout the year. Specifically, the highest increase in the number of international tourist arrivals was recorded in Asia, followed by Africa, America and Europe. The only region that presented a decline throughout the year was the Middle East. It is estimated that the volume of outbound trips will grow by $4 \%$ to 947 million in 2013 and the number of overnight stays will also increase by $4 \%$ to just over 7.5 billion nights by the year's end and the industry will witness surge in growth and economic development and will perform better than previous year (UNWTO Annual Review, 2010).

Tourism sector has emerged as an important sector of Indian economy and contributes substantially in the country's Foreign Exchange Earnings. Tourism is the third largest foreign exchange earner after gems and jewellery and readymade garments and represents vibrant economic sector with overwhelming growth and revenue generation (UNCTAD Annual Report, 2007). Foreign Exchange from tourism, during 2012 was Rs.77,591crore, with a growth of 19.6\%, as compared to Rs.64,889 crore during year 2011. The Foreign Tourist Arrivals (FTA's) in India have increased from 5.11 million in 2009 to 5.58 million in 2010. The compounded Average Growth Rate (CAGR) of the tourism sector in India from 2001 to 2010 is around 8\%(WEF Annual Report, 2009).The importance of tourism as a creator of job opportunities can be understood from the fact that in India every one million invested in tourism creates 47.5 jobs directly and around 85-90 jobs indirectly in comparison, agriculture creates only 44.6 jobs and manufacturing a mere 12.6 jobs and will thereof attract heavy foreign investment in the sector on development of better service capacity and world class infrastructure (World Bank Annual Report, 2010).

Tourism product renewal strategy can consist of the increase of the activity of some travel arrangement for the present travel consumers without operating deep changes (for instance, offering supplementary services, installing pools or fitness centers within the accommodation unit); Making some important modifications in the product structure though without its nature (for instance, the increase of the classification of a hotel product).

One notices the fact that in tourism the structure of a product can be changed much easier than in other domains. The modular character of the tourist product allows some modifications of the transport, accommodation, public supply or divertissement services offered to the consumer or of the tourist tour configuration.

The diversification strategy implies the simultaneous development of new or improved tourist products and of the new markets (for instance, a tour operator specialized in the soft tourism can vary his mix of products offering also tourist tours with cultural character or treatment vacations in balnear resorts). This type of strategy allows the realization of a medium and long term flexibility of the derived tourist offer. The strategies of the low season travel product are specific to the hotel industry.

Therefore, marketers will have to counterbalance the decrease of the activity of the travel destinations in low seasons by diversifying the services and products on the market. In this respect, we notice the making of some tourist arrangements (of the type "trip + trip" or "trip + tour") in which there are combined attractively elements with different degrees of seasonality (seaside, mountain, delta, 
monasteries, balnear resorts). The accessibility degree of a tourist product in low season can be increased by including in the proposed arrangement a minimum set of exercises (for instance, in case of a trip, the tourist can choose for accommodation with half board or only for accommodation) and by establishing a minimum period for the trip (tourists having the possibility to prologue it according to their incomes and their satisfaction degree for that particular tourist destination). The attractiveness of the low season tourist product can be increased by offering some varied divertissement options at the destination place, (for instance, hunting or fishing programs, riding, different trips, folk programs, hiking, etc.).

According to the price level and accessibility the following price strategies can be seen: high price strategy (practiced in case of exclusivity of the offer or in case of limitation of the competition's offer), contractual price strategy (contractual, inclusive, "all inclusive”), differentiated rates strategy (characteristic to the tourism industry), discount and bonus strategy (adopted by tourism companies who adjust basic prices of products in order to stimulate a certain type of clients, that is: clients who ask for a high volume of services, clients who accept vacations during low seasons).

The distribution strategies adopted by tourism operators take into consideration: the sale of a tourist service by going to more agents, to the same consumers' segment, the sale of the same product through different channels of distribution to various segments of public consumers, the sale of more products through different distribution channels to one or more consumers' segments on the market. As one can easily notice, in this attempt to classify the component objects of strategies, the quantitative criterion is very important, the three aimed elements - tourist service, distribution channels, consumer segments - being involved (combined) in different numerical proportions.

From the number of agents perspective (together with their location) we can see three strategic options of tourism distribution: Exclusive distribution is the restriction of a small number of agents (even only one) who exercises - on a certain market or geographical area - the exclusivity of distributing products or tourist services, as a given and assumed privilege through contractual conditions that govern the relation provider - distributor.

Selective distribution implies choosing and using a number of limited agents whose distribution activity is appreciated as being more efficient than the competition's, having the possibility to ensure a higher volume of sales for the tourist products. Adopting this strategy allows the tourist unit to perform a more efficient control over certain market segments, in the conditions in which they have less expenses. If the distributors show different trade qualities from one case to another, the tour operator can for instance renounce to those less efficient in order to concentrate its attention upon the more dynamic sales offices, to whom it can offer increased commissions, according to the reached objectives. Intensive distribution implies the use of a big number of channels and agents through which the services reach the final consumers. When a tour operator is not sufficiently known on the tourist market it will seek to sell its offer through a very big number of distributors to increase the number of sold products and to make a name. In case of important market segments characterized through a big number of possible tourists it is recommended to use extended distribution systems, with lots of agents. More, in case on a certain market there are conflicts between competing tourists companies who apply an intensive distribution strategy, having a great number of distribution units, it is less possible that a tourist company enter in competition by selecting a limited number of agents.

On the tourist market there is a tendency of vertical integration of accommodation, transport, trip planning and distribution activities, therefore have appeared many companies that are able to ensure all of these services under the form of a package. In this way, touristic operators as Club Méditerranée, Nouvelles Frontières, TUI represent examples of successful integration of the distribution network. The main objectives that they had in mind were the improvement of the control over the tourist product, to beneficiate of smaller distribution prices, and use immediately the amount cashed from clients even before they began their trip.

\section{TOURISM SCENARIO IN JAMMU AND KASHMIR}

The tourism represents the major industry in Jammu \& Kashmir. It is playing an important role for developing the economy, particularly in the regions of Kashmir Valley and the Ladakh. The industry provides jobs to a very large number of people and generates economic activities in the primary, secondary and tertiary sectors in the State. According to Centre for Monitoring Indian Economy (CMIE), the tertiary sector in the state contributes nearly44.2 per cent to the states GSDP (at current prices, 2007- 08) (Ministry of Tourism Annual Review, 2012).

Amongst the various sectors coming under tertiary sector, Tourism is a key contributor to the sector having annual growth of 8.7 per cent(WTTC Report, 2010).According to the statistics, the annual growth rate of the domestic tourists is increasing, but, with a declining growth rate i.e. 20.9 percent for 2009 to 8percent in 2010. On the contrary,figures on foreign tourist arrivals show a major decline in the growth rate, probably due to the security/law and order issues. In year 2008 the number of domestic tourists visiting state where 76.39 lakh, whereas the foreigners where 0.55 lakh and the number of visitors has shown improvement in 2010 with over a crore tourists visiting state (Ministry of Tourism Report, 2012).The government of Jammu \& Kashmir has now started to adopt perspective planning for the development of tourism industry in the state and has focused on comprehensive approach towards betterment of service infrastructure in 
order to attract and increase influx of tourists both domestic as well as foreigners (MSME-DI Annual Review, 2011).

The tourism industry of the state is promoted mainly by Jammu \& Kashmir Tourism Development Department and Jammu \& Kashmir Tourism Development Corporation, which are the main developmental, promotional and regulatory organizations of the J\&K State Government. These organizations are looking after overall planning and execution of schemes for the development, up-gradation and improvement of the tourism infrastructure in different parts of the State.

They are also undertaking promotional activities like providing support to the private sector industry in the form of incentives for setting up various tourist facilities as well as for promotion and marketing of their products and services by organizing international and national tourism festivals and events and secondly promotion and marketing of various tourist destinations in the form of packages to foreign and domestic tourists i.e Gulmarg for Ski, Pahalgam for White River Rafting and Ladakh for Trekking and Mountaineering (J\&K Statistical Digest, 2012). The tourism department has created a vision document and a roadmap for development of tourism in the state of Jammu \& Kashmir. The department has envisaged to adopt diversified strategy by highlighting key tourism concentric features of Jammu, Kashmir and Ladakh and side by side developing tourism related infrastructure and also aligning private players through public-private partnerships.

It is clear that government initiatives along with private enterprises effort have given edge to the tourism development activity in the state and future is seen in optimistic terms and opportunity for everyone. It is in this regard this paper provides a review of strategic planning research and makes a contribution to the literature by adopting a modern and broad conceptualization of strategic planning that can be used to improve the tourism sector of Jammu and Kashmir.

\section{METHODOLOGY}

Various scholarly articles were identified using multiple databases that include Emerald Insights, Elsevier, Sage, EBSCO, Pro-Quest Education Journals etc. Other than these databases, Sci-hub, LibGen, Google Scholar, Researchgate etc. have been used to download the papers.

With the research focus on tourism, the keyword combination of "tourism and strategies" and "tourism and strategic planning” was used to result in 123 articles found. Other than these keywords, databases were also searched by key words like 'strategic planning, tourists, tourism management'. There were such restrictions as peer-review, empirical study, and English publication, but no restriction was placed on publication dates.The articles published from 1998 were covered that were pertaining to tourism strategies. Then, the titles and abstracts of the articles were reviewed to determine whether each study (a) focused on the understudy variable, (b) had a research methodology, and (c) examined empirical data .In the following stage, the studies whose abstracts provided vague descriptions of the research frameworks and measurements were reviewed indepth for inclusion or otherwise. Those studies were excluded that were purely conceptual with no report of measurements. As a result of this staged review, 123 articles were obtained. All the abstracts of 123 articles were reviewed, out of which only those empirical studies were chosen for further in-depth analysis that were based on the objectives laid down for the study.

\section{RELATED LITERATURE}

The review of literature reflects that the government as well as the companies has been adopting various strategies for promotion of the tourism sector in the state. However the development of tourism sector needs effective strategies in the state. The strategies could be mainly based on differentiation, which the J\&K enjoys as compared to the other states of India. The strategies can be persuaded at the level of the government as well as at the level of the organizations / tourism players involved with the tourism sector.

Buhalis, (1998), argued that two strategic directions could be followed: tourism organizations could either offer differentiation value, by designing high quality personalized arrangements, which customers would be willing to pay a premium for, or they could offer cost value by delivering less expensive products than competitors, through standardization, high volume and consolidations. However moulding service parameters to cater to differentiated customers will pose an challenge to marketers and therefore opting focused strategy taking both focused differentiation and standardization into consideration will develop world tourism industry on longer terms for future.

Likewise, Bosselman, et al. (1999), emphasized that managing tourism growth requires an analysis and evaluation of methods by which communities can carefully control tourism in order to maximize its positive aspects while minimizing its detrimental effects. The uncontrolled tourism can adversely affect a community and requires creation of an effective strategy that can protect tourism resources for current and future generations. The requirement of sustainable tourism development strategy is needed, which can be opted to promote tourism and which is more environmentally concerned.

Similarly, Grönroos (2000), states that the quality of a service as it is perceived by customers has two dimensions; a technical or outcome dimension and a functional or process-related dimension and continues: various services such as technical service - provide added value, which is partly of a technical nature (that is, adds to technical quality) and partly of a functional nature (that is, adds to 
functional quality)". A well done reservation has both of these dimensions and it is important that they both are taken seriously as they affect directly to customer satisfaction. Therefore for promotion of tourism business it is important that variability in strategy across differential dimensions are adopted keeping in view core competence and service requirements. On the other hand, Dieke (2000), revealed that tourism grew rapidly, aided by major European tour operators who invested in accommodation and transport, yet stalled 10-15 years later when these destinations became overcrowded and unfashionable, and the operators pulled out. In the bank, projects that continued to be implemented during the 80's performed poorly. The operators used expansion strategy to improve the infrastructure capacity to accommodate tourists from multiple destinations and thereafter followed retrenchment by selling of assets to local enterprises and diversifying into new business domains.

Dane, Suzanne, and Amy Jordan Webb. (2001), highlights a variety of approaches in dealing with different aspects of tourism. Although not exclusively rural in focus but with mixed urban tinge and proposes to develop an strategy which studies the modern infrastructural demand and its implications on development of tourism industry. As it is evident that infrastructural facilities are the required impetus for catering high profile tourists and therefore have effective role in creation of heritage trails and cultural corridors through craft trails, and festivals. In the same year Shaffer (2001), describes both the modern marketing strategies used to promote tourism and the messages of patriotism and loyalty embedded in the tourist experience and therefore linking tourism to the simultaneous growth of print media, a national market, and a middle class with money and time to spend on leisure. The evolution of a new category of customers called as middle class who have limited money at disposal but constitutes a large class of people and therefore represents an opportunity to be cater on. Being highest customer base and divergent service requirements provides impetus for the development of tourism industry.

Holloway, (2004), points out that there are four main characteristics of tourism services: intangibility, heterogeneity, perishability and inseparability. Intangibility means that the product is not available for testing before it is actually purchased so there is always a risk involved for the buyer. It also means that in place for a distribution system there is a reservation system which is the industry's tool for coping with demand and supply. Het-erogeneity is the idea that a service product is never exactly the same due to uncontrollable factors such as weather conditions and individual employee's work performances.

Perishability indicates that the service product which has not been sold today cannot be stored and sold tomorrow but it is gone forever. The tourism business development strategy revolves around the featured characteristics and their usage in communicating the true value of the service. Likewise, Elliott and Mann, (2005), stressed that tourism's role in development has evolved significantly, providing not just foreign exchange, economic growth and employment, but also opportunity for host community participation in biodiversity conservation, urban growth, infrastructure overhaul and planning, rural development, environmental restoration, coastal protection and cultural heritage preservation. Based on the findings from their study it was found that tourism has a role to play in a greater number of developing economies than ever before and development agencies are progressively becoming involved in this sector. Further, Jackson(2006),exemplified that in recent years, the government has decentralised many elements of tourism to regional authorities. There is a growing recognition of the importance of local and regional tourism authorities and of promoting tourism. Similarly, co-operation between regions is encouraged to provide joint tourism routes, so that more regions can benefit from tourism and help to maximise profits. The focus has shifted from local tourism promotion to global destination promotion and the strategic shift from local strategy to global strategy has been seen as a new paradigm in tourism business management across Europe, America \& Asia.

\section{DESTINATION STRATEGY}

According to Diamond (1977), destination strategies can be of four types. These were - turnaround strategy, sustainable growth strategy, incremental growth strategy and selective tourism strategy. Turn around strategic approach was resource intensive, demanding a public sector lead and backing from both the industry and residential population. Sustainable growth strategy was less dramatic than turnaround strategy and relied on gradual replenishment of declining markets by seeking out new areas of market potential. However, the original market, though reducing was still nurtured and maintained. This was more of a marketing-led approach with lower levels of investment. Incremental growth strategy on the other hand sought a new market and product development was phased over a number of years through test marketing and development projects. Selective tourism strategy relied upon accurate indication of new growth markets. According to him the most appropriate strategy for each resort/destination was dependent on a variety of factors. These were- estimating market, stage in the product life cycle, competitive position of the resort, political and community support, attitude of the tourism industry, available investment and public funds.

According to Porter (1980), tourism strategy took the three forms. These were-(i) lower costs where production efficiency led to value added to both consumer and producer matching market prices with greater profitability or being able to offer lower prices while maintaining average profits. (ii) Differentiation, where additional value was created for the consumers through adding value that allowed a greater price to be commended e.g. branding, product features or additional benefits or support. (iii) Focus, relating to the breath of market, scope, focuses referring to targeting specific niche markets or product ranges. Porter also opined that the essence of strategy formulation was coping with 
competition where competition in an industry is rooted in its underlying and competitive forces. Porter (1980) also brought to light the competitive strategy of an organization( destination) that was dependent on a detailed understanding of the nature and strength of each of the five forces ( threats of new competitors; threat of substitute products; the power of buyers: power of suppliers; rivalry among business houses in the industry.

According to Porter (1985), competitive advantage raised from selection of the generic strategy which best fitted the organization's competitive environment and then organizing value adding activities to support the chosen strategy. There were three main alternatives, which were (i) differentiation:creating a customer perception that product is superior to those of competitors so that premium price can be charged. (ii) cost leadership:- being the lowest cost producer of a product so that above average profits are earned even though the price charged is not above average. (iii) focus:utilizing either a differentiation or cost leadership strategy in a narrow profile of market segment(s).

Porter (1990) argued that global competitive advantage was dependent upon two sets of decisions, these were- (i) configuration of value adding activities: managers were the authority to decide in which nations they would carry out each of the activities in the value chain of their business. Configuration could be broad (involving many countries) or narrow (one or few countries). (ii) Coordination of value adding activities- managers must decide the most effective way of coordinating value adding activities, which were carried out in different parts of the world. For Porter, the 'purest global strategy' was when an organization concentrated key activities in locations offering competitive advantages and coordinated activities on a global basis. According to him, 'organizations should move towards purest global strategy in the long run.

Yip (1992) argued that successful global strategy even for tourism were based upon a comprehensive analysis of globalization drivers as these were the means of industry and market analysis to formulate the global strategy. Yip identified three stages in developing a total global strategy. These were- (i) Developing a core strategy:- it involved building core competences and generic or hybrid strategies which could potentially give global competitive advantage. (ii) Internationalizing the core strategy:- it included the choice of which markets the business would enter and the means by which the organization would enter them. In this stage the core competences and generic strategy were introduced to international markets and when the organization began to locate its value adding activities in locations where competitive advantages like low cost access to resources are available. (iii) Globalizing the international strategy:- this stage was based upon coordinating and integrating the core competences and strategy on a global basis. It would also include deciding which elements of the strategy to be standardized and which were to be locally accepted on the basis of the strength of the globalization drivers in the industry and market.

\section{STRATEGIC PLANNING APPROACH FOR DESTINATION DEVELOPMENT}

In his book "Tourism: How effective management makes the difference”, Doswell, R. gave a framework for tourism strategy. This framework deals with the tourism development policies, region's macroeconomic perspectives with respect to the contribution of tourism industry, contexts in which tourism growth and development are expected, characteristics of demand and supply, marketing opportunities in various segments, tourism development areas as administrative units, infrastructural situations, description of the needed product development, indication of the expected volume of tourists and receipts, regulatory framework, human resource development program and public awareness program.

Faulkner (2001) viewed an integrated plan of action with goals and objectives focused on those actions and systems which monitored progress the strategy process for corporate, strategic and marketing planning has also been said to consist of a series of steps , these being formulation, implementation and evaluation (Varadarajan \& Jayachandran 1999)'. Cespedes (1991) argued that tourism strategy was accepted to be interactive in nature. Veal A. J.( 2003), described the terms strategic planning and strategic management in tourism as an approach to planning and management that sought to ensure that medium- to longterm goals were given prominence, and day-to-day management was harnessed to the achievement of such goals rather than being distracted by ad hoc, short-term objectives.

This approach had its origins in the private sector but, since the 1960s, public bodies increasingly felt the requirement to behave much like private corporations, preparing strategic plans, which were rolled forward annually and which integrated forward planning with budgeting, implementation strategies and performance appraisal.

The terms strategic planning and strategic management were used interchangeably by some, but strategic planning was considered here as the initial process of preparing a direction and broad program of activity for the organization or development corporations while strategic management, on the other hand, was seen as those aspects of management which were concerned with ensuring that the strategic plan was implemented and that the organization did not lose sight of its strategic directions because of day-to-day activities. Veal A.J.(2003), introduced a strategic planning process with chronological six steps viz. terms of reference, environmental appraisal, mission/goals, development of options, evaluation of such options and decide strategies. In his book "Travel and Tourism Management" Singh S.P.(2006) discussed various aspects of strategic managements keeping in view the present challenges and 
stiff competition as managers needed to learn and implement these strategies successfully. The present book discussed various strategies like competitive, generic, cost leadership differentiation, focus, stability, retrenchment, total global, global generic, core competence, development, evaluation, implementation and globalization. In this endeavor, the book elucidated on many important topics like strategic direction, mergers, acquisitions, joint development, strategic alliances, diversification and globalization along with trends of strategic management.

\section{CONCLUSION AND DISCUSSION}

The tourism industry of the state is promoted mainly by Jammu \& Kashmir Tourism Development Department and Jammu \& Kashmir Tourism Development Corporation, which are the main developmental, promotional and regulatory organizations of the J\&K State Government. These organizations are looking after overall planning and execution of schemes for the development, up-gradation and improvement of the tourism infrastructure in different parts of the State.

They are also undertaking promotional activities like providing support to the private sector industry in the form of incentives for setting up various tourist facilities as well as for promotion and marketing of their products and services by organizing international and national tourism festivals and events and secondly promotion and marketing of various tourist destinations in the form of packages to foreign and domestic tourists. With the research focus on tourism, the keyword combination of "tourism and strategies" and "tourism and strategic planning” was used to result in 123 articles found. Other than these keywords, databases were also searched by key words like 'strategic planning, tourists, tourism management'. There were such restrictions as peer-review, empirical study, and English publication, but no restriction was placed on publication dates.

The articles published from 1998 were covered that were pertaining to tourism strategies. Then, the titles and abstracts of the articles were reviewed to determine whether each study (a) focused on the understudy variable, (b) had a research methodology, and (c) examined empirical data .In the following stage, the studies whose abstracts provided vague descriptions of the research frameworks and measurements were reviewed in-depth for inclusion or otherwise. Keeping in view all this, review of various strategies that can be adopted for the development of tourism sector was the focus of the study.

\section{REFERENCES}

[1] Bosselman, F.B., Peterson, C.A. and McCarthy, C. (1999). Managing Tourism Growth: Issues and Applications. Island Press, Washington, DC.

[2] Buhalis, D. (1998). Strategic use of information technologies in the tourism industry. Tourism management, 19(5), 409-421.
[3] Cespedes, F. V. (1991). Organizing and implementing the marketing effort.

[4] Dane, Suzanne, and Amy Jordan Webb. (2001). Share Your Heritage: Cultural Heritage Tourism Success Stories. Washington, DC: National Trust for Historic Preservation.

[5] Diamond, J. (1977). Tourism's role in economic development: the case re-examined. Economic development and cultural change, 25(3), 539-553.

[6] Dieke, P. U. (2000). The political economy of tourism development in Africa. Cognizant Communication Corporation.

[7] Elliott, S. M., \& Mann, S. (2005). Development, poverty and tourism: perspectives and influences in Sub-Saharan Africa. Occasional Paper Series, 1-11.

[8] Faulkner, B. (2001). Towards a framework for tourism disaster management. Tourism management, 22(2), 135-147.

[9] Grönroos, C. (2000). Service management and marketing: A customer relationship management approach.

[10] Holloway, J. C. (2004). Marketing for tourism. Pearson education.

[11] Jackson, L. A. (2006). Ameliorating the negative impacts of tourism: a Caribbean perspective. International Journal of Contemporary Hospitality Management.

[12] Porter, M. E. (1980). Competitive strategy. New York: The Free Press.

[13] Porter, M. E. (1990). New global strategies for competitive advantage. Planning Review.

[14] Porter, M. E.(1985). Competitive advantage: creating and sustaining superior performance. New York, NY: Free Press.

[15] Shaffer, M. S. (2001). Seeing the Nature of America: The National Parks as National Assets, 1914-1929. Being Elsewhere: Tourism, Consumer Culture and Identity in Modern Europe and North America, 155-184.

[16] Singh S.P.(2006).Travel and Tourism Management.

[17] Varadarajan, P. R., \&Jayachandran, S. (1999). Marketing strategy: an assessment of the state of the field and outlook. Journal of the academy of marketing science, 27(2), 120-143.

[18] Veal, A. J. (2003). Tracking change: Leisure participation and policy in Australia, 1985-2002. Annals of leisure research, 6(3), 345-277.

[19] Yip, G.S. (1992), Total Global Strategy: Managing for Worldwide Competitive Advantage, Prentice-Hall, Englewood Cliffs, NJ 